\title{
The development of a food-packaging database based on intakes of packaged foods in Irish teens (13-17 years)
}

\author{
A. Connolly, E. Boylan, A. Nugent, A. Hearty and M. J. Gibney \\ UCD Institute of Food \& Health, School of Agriculture, Food Science and Veterinary Medicine, University College Dublin, \\ Belfield, Dublin 4, Republic of Ireland
}

Consumption of packaged foods by Irish children has previously been investigated ${ }^{(1)}$. Following on from this investigation a food packaging database was developed to quantify and provide information on the types of packaging materials used with foods consumed by Irish teens, particularly those that may have migratory compounds. This information was collected from a sample of 441 Irish teens aged between 13 and 17 years in The National Teens' Food Survey ${ }^{(2)}$. Using $7 \mathrm{~d}$ food diaries the participants were asked to record a detailed description of the food they consumed, weight and the packaging used. Packaging was collected and forwarded to the coordinating centre and entered into a Microsoft Access database, in which seventeen packaging groups were developed, e.g. plastic, canned. Each eating event in the food survey was recorded and entered into the database at brand level and nineteen food groups were created to aid further analysis using SPSS $v 12$ (SPSS Inc., Chicago, IL, USA). Data from the packaging database was merged with the food consumption data at brand level. Based on eating occasions from the survey, packaging usage was compared across the nineteen food groups.

Table. Packaging groups and most common food groups associated with them

\begin{tabular}{|c|c|c|c|c|}
\hline Packaging type & $n$ & $\%$ & Most common food group & $\%$ \\
\hline Plastic (excluding metallised) & 18996 & 40.9 & Beverages, including milk, and yogurt & 14.5 \\
\hline Unknown & 7073 & 15.2 & Beverages & 35.1 \\
\hline Paper or board & 6664 & 14.3 & Sugars, preserves, confectionery and savoury snacks & 23.9 \\
\hline Loose or unpackaged & 4046 & 8.7 & Fruit and fruit juices & 23.9 \\
\hline Tetra-Pak & 2410 & 5.2 & Milk and yogurt & 57.4 \\
\hline Metallised plastic & 2114 & 4.5 & Sugars, preserves, confectionery & 76.8 \\
\hline Plastic and paper or board & 1117 & 2.4 & Butter, spreading fats and oils & 71.1 \\
\hline Canned & 968 & 2.1 & Beverages & 47 \\
\hline Glass and metal & 876 & 1.9 & Soups, sauces, miscellaneous products & 43.5 \\
\hline Plastic and metal & 828 & 1.8 & Milk and yogurt & 35.7 \\
\hline Foil & 613 & 1.3 & Sugars, preserves, confectionery & 69.8 \\
\hline Glass and plastic & 276 & 0.6 & Sugars, preserves, confectionery & 25.7 \\
\hline Metal with paper and board & 201 & 0.4 & Sugars, preserves and confectionery & 19.4 \\
\hline Soup- and sauce-type packet & 199 & 0.4 & Soups, sauces, miscellaneous products & 77.9 \\
\hline Glass & 50 & 0.1 & Soups, sauces, miscellaneous foods & 26.0 \\
\hline Glass with paper and board & 26 & 0.1 & Beverages & 53.8 \\
\hline Waxes & 15 & 0.0 & Cheeses & 78.6 \\
\hline Total & 46472 & 100 & & \\
\hline
\end{tabular}

The Table lists all types of the packaging groups recorded over the 46472 eating occasions, with plastic by far the most common packaging group recorded $(n=18996,40.9 \%)$. Milk and yogurt $(14.1 \%)$ was the most common food group noted within the plastic group. These results illustrate the high percentage of foods packaged using non-metallised plastic in particular, and may warrant further investigation on the possible migratory effects this packaging may have on the food in the human diet.

1. Duffy E, Hearty AP, Gilsenan MB \& Gibney MJ (2006) Food Addit Contam 23, 623-633.

2. Irish University Nutrition Alliance (2008) The National Teens' Food Survey. http://www.iuna.net 